\title{
Female Genital Cutting: Cultural Rights and Rites of Defiance in Northern Tanzania
}

\author{
Anna Winterbottom, Jonneke Koomen, and \\ Gemma Burford
}

\begin{abstract}
This article reviews campaigns against female genital cutting (FGC) directed at Maasai communities in northern Tanzania. The authors argue that campaigns against FGC using educational, health, legal, and human rights-based approaches are at times ineffective and counterproductive when they frame the practice as a "tradition" rooted in a "primitive" and unchanging culture. We suggest that development interventions that do not address local contexts of FGC, including the complex politics and history of interventions designed to eradicate it, can in fact reify and reinscribe the practice as central to Maasai cultural identity.
\end{abstract}

\section{Introduction}

Female genital cutting (FGC) has attracted attention from human rights organizations, governments, legal experts, and scholars worldwide. ${ }^{1}$ Since the 1980s many nation-states have adopted legislation to ban the practice of

African Studies Review, Volume 52, Number 1 (April 2009), pp. 47-71

Anna Winterbottom currently holds a Wellcome Trust scholarship for doctoral study at Queen Mary, University of London. During a residence at the British Institute in East Africa in 2004-5 she conducted research into historical contexts of government policy in Kenya, Uganda, and Tanzania. She has worked with several NGOs in the U.K. and East Africa and began the research for this article while volunteering for Aang Serian during 2006.

Jonneke Koomen is a doctoral candidate in the Department of Political Science at the University of Minnesota. Her research examines the local politics of international efforts to promote women's human rights in East Africa. She conducted fieldwork on gender and global governance in Tanzania between 2005 and 2007.

Gemma Burford is International Liaison Officer for Aang Serian, where she was also actively involved in planning and monitoring the organization's project to reduce the prevalence of FGC within the Maasai community. Her research focuses on indigenous and traditional systems of health care. 
FGC, and widespread education programs attempt to address the implications of female circumcision for women's rights and health. However, closer attention to the cultural and historical contexts of the various practices known as FGC is necessary in order to understand the continued failure of many of these efforts.

Scholars have questioned the dichotomies of tradition and modernity, power and culture, and locality and globalization that once guided the anthropological study of "traditional" culture and cultural practices (Wolf 1982; Appadurai 1996; Gupta \& Ferguson 1997). Since Ferguson (1990) highlighted unintended consequences of development campaigns, researchers increasingly address questions of power within the discourses and practices of development. In her research on Tanzanian Maasai communities, Hodgson (2001a) shows that misleading characterizations of these pastoralist societies as static, isolated, and traditional throughout the colonial and postcolonial eras both undermined development interventions and, at times, provoked resistance from rural Maasai.

In this article we draw upon these explorations of power and culture in development practice to argue that simplistic characterizations of FGC as a "tradition" and a "cultural practice" by governments, NGOs, international organizations, and activists can be counterproductive. In fact, we suggest that laws intended to prevent FGC may at times even serve to perpetuate the practice. Furthermore, human rights-based approaches can often be ineffective when communities feel that their rights to cultural self-determination are infringed. Similarly, anti-FGC education may not be well received when undertaken by institutions perceived as hostile to minority ethnic or cultural groups. We argue that approaches that emphasize the medical implications of FGC will succeed only if they address local beliefs about health. Simplistic views of "tradition" as sets of static practices, posited in opposition to universal rights, conceal complex changes in patterns of cultural behavior. We present a case study of the reaction of Maasai communities in northern Tanzania to attempts by government agencies and NGOs to end the practice, and we discuss community-led changes in rite-of-passage ceremonies.

\section{FGC and Contemporary Anti-FGC Campaigns in Tanzania}

The Tanzanian Demographic and Health Survey (TDHS) of 2004-5 reports that roughly 15 percent of Tanzanian women ages 15 to 49 are circumcised, down from an estimated 18 percent in 1997. The TDHS also reports lower rates of circumcision among girls ages 15 to 19 compared to older women (National Bureau of Statistics 2005:13.2; see also UNICEF 2005:4). The focus of our study is the Arusha region of northern Tanzania, an area that historically has one of the highest rates of FGC in Tanzania. Although the 2004-5 TDHS reports a significant reduction in the prevalence of FGC in this area (from an estimated 81 percent in 1996 to 54.5 percent today), this 
change can be attributed to the recent division of the region into Arusha and Manyara: the prevalence in Manyara remains at 81 percent. Moreover, any decreases may reflect underreporting as a result of the prohibition of FGC since the previous survey. The most recent TDHS reveals a difference in prevalence of FGC between rural and urban areas, with the former standing at 17.6 percent and the latter at 7.2 percent. There are, to our knowledge, no statistical indicators that examine the practice of FGC across different ethnic or linguistic groups in Tanzania. However, given that Maasai make up a large proportion of the population of the Arusha and Manyara regions-which correspond roughly to the Maasai District of colonial Tanganyika-it is reasonable to assume that the figures for these regions imply a high rate of circumcision among rural Tanzanian Maasai. ${ }^{2}$

Tanzania, like many African countries, has seen a resurgence of antiFGC campaigns since the 1990s. ${ }^{3}$ Though FGC has been an offense prosecutable under the Tanzanian criminal code since 1995 (Boyle et al. 2001), the Sexual Offence Special Provision Act of 1998 explicitly criminalized the circumcision of girls under the age of 18 years. The Ministry of Health runs anti-FGC programs in conjunction with NGOs, including awareness and education programs (Rahman \& Toubia 2000:224). The Ministry for Health and the Ministry for Community Development, Gender and Children have formulated a fifteen-year plan to eradicate FGC by the year 2015 that is supported by the WHO, UNICEF, and UNFPA (United Republic of Tanzania 2003). There are also numerous civil society efforts to combat FGC in Tanzania. The Tanzanian Media Women's Association (TAMWA), the Legal and Human Rights Centre (LHRC), and the Tanzanian Women Lawyers Association (TAWLA) lead a coalition of NGOs working to eradicate FGC through educational and advocacy programs, media campaigns, and research projects. ${ }^{4}$ Like the government, civil society organizations often obtain funds for anti-FGC campaigns from foreign governments, foundations, and religious groups such as the Konrad Adenauer Foundation, USAID, and the New York-based organization Equality Now. There are also many small-scale programs organized by local charities, churches, schools, and community groups that often have only tenuous links to national and global institutions. Despite some evidence of tensions between local and international approaches to the issue of FGC, "indigenous" movements across Africa are nevertheless likely to draw inspiration from international declarations and debates on FGC, not least because of the need for external funding (Rahman \& Toubia 2000; Hernlund 2000).

\section{Historical Contexts}

FGC is typically described by those who practice it and by those who seek to eliminate it as a "traditional practice." Maasai circumcisers questioned about the reasons for the practice often answered simply, "it is our culture," "we just found it," or "our grandmothers gave it to us" (interviews, Mon- 
duli, June 29, 2006). FGC is often associated with other markers of tradition including tribal dress, drinking blood and milk, ear-stretching, and mud houses. In this section, we argue that the identification of FGC with these hallmarks of Maasai pastoralist culture contributes to the widespread image of the "backward" Maasai in the popular imagination, as well as the identification of FGC as an essential and unchanging part of their culture by Maasai themselves (Talle 1999; Hodgson 2001a; Bergner 2006).

Maasai communities have long histories of complicated and highly politicized interactions with local, national, and international organizations that seek to promote "civilization," development, and modernization. Colonial and postindependence governments have treated the seminomadic pastoralism of the Maasai as a cultural pathology associated with a "backward" way of life (Hodgson 2001a, 2005).$^{5}$ The "stubborn traditionalism" of the Maasai is widely viewed as the main barrier to school attendance and female empowerment. As Hodgson (2001a:2) notes, female circumcision among the Maasai is often similarly attributed to their cultural isolation and ignorance, the stubborn persistence of apparently static customs, and an "unwillingness to change." Interventions aimed at ending the practice of FGC must therefore be contextualized within this politicized and troubled history if we are to understand community responses to contemporary campaigns against FGC.

\section{Colonialism and the Birth of "Development"}

Historians have argued that developmentalism became a state ideology in East Africa after the 1940s, when colonialism increasingly became the target of nationalist and international critiques (Cooper 2002). In Tanganyi$\mathrm{ka}$, this involved promoting large-scale "scientific" agricultural and irrigation schemes and monetization, including mandatory cattle sales. The 1951 Maasai Development Plan promoted land alienation without the consent of Maasai elders and raised taxes in the name of development. The failures of most of these schemes were widely attributed to the "cultural conservatism" of the Maasai. This charge was used to reassign Maasai pastoralist lands to "more productive" African cultivators or European settlers, while also undermining Maasai attempts to cultivate the land. A similar exercise in colonial hypocrisy took place in the provision of schooling. Under indirect rule, the British colonial administration deliberately limited the number of schools in the Maasai Reservation, ostensibly to "protect" the Maasai from "corrupting influences" (Hodgson 2005:10). After the shift toward modernist ideologies, the reluctance of parents to send their children to schools was attributed to a stubborn resistance to change among the Maasai. ${ }^{6}$

It was in this politicized context that colonial anti-FGC campaigns in East Africa took place. While little information is available for Tanganyika, colonial campaigns in Sudan and the Meru region of Kenya have been more thoroughly documented. Women's bodies were symbolic battlegrounds in 
many anticolonial struggles. In 1945, British colonial authorities in Sudan announced plans to outlaw female infibulation. Immediately "parents rushed to have their daughters infibulated," resulting in "an unprecedented orgy of bloodletting" (Boddy 1991:16; see also Boddy 2007). When a circumcision case was brought to trial, it triggered such violent anticolonial demonstrations that officials soon ceased enforcing the controversial policy. In the Meru region of Kenya the "native" authorities banned female excision in 1956. This law provoked the Ngaitana ("I will circumcise myself') movement, in which pubescent and prepubescent girls circumcised each other en masse (Thomas 2000:137,141). As a result, more than twentyfour hundred girls and their parents were taken to court and punished with large fines, imprisonment, and hard labor. These measures failed to effect change, however, and as in Sudan, the law was abandoned within a few years. Participants interviewed by Thomas (2000:141) argued compellingly that "the ban encouraged rather than deterred excision." As the independence movement in Kenya evolved, FGG became increasingly politicized as a symbol of Mau Mau membership.

It is important not to assume too much congruence between these cases from Sudan and Kenya and Tanzania: no such high-profile measures against those practicing FGC are recorded in colonial Tanganyika, nor did the issue become as politicized. However, these examples illustrate the effects of attempts to end the practice of FGC within the context of the general assault on "culture" and "tradition" launched in the name of development in the last two decades of colonial rule in East Africa. As we show below, contemporary campaigns often echo both the language and practices of colonial development efforts. When "development" and "civilization" involve the forcible removal of land in return for little or no tangible benefit, those on the receiving end of these modernizing campaigns often decide that the "cultural traditions" undermined by these concepts must be protected at all costs. Therefore, both in the colonial period and today, attacks on the "barbarous" and "primitive" custom of FGC may, counterintuitively, politicize it as an essential component of Maasai cultural identity.

\section{Maendeleo: Official Development Ideology in Postcolonial Tanzania}

After Tanzanian independence in 1961, the doctrine of maendeleo (development) was central to President Julius Nyerere's vision of a self-sufficient socialist African nation. During this period there were strong efforts to create a uniform culture, with different tribal traditions homogenized to create a nation in which "we are all Swahili" (Nyerere, cited by Geiger 2005:284). The vision was of a country where people spoke Swahili, practiced "modern" agricultural methods in the communal ujamaa ("family") villages to promote independent wealth, and owed primary allegiance to the nation rather than to local political systems. Minority groups who refused to "become Swahili" were seen as the custodians of "primitive customs," which 
were in turn attributed to "ignorance." These customs were viewed by the postcolonial Tanzanian government as representing "tribalism" and undermining efforts to build national unity, a view apparently shared by many members of the educated elite (Hodgson 2001b:121). Along with continued land alienation, this period saw the exclusion of Maasai from most state development projects and direct assaults on Maasai cultural symbols, including opposition to "traditional" loaf-shaped houses, efforts to promote the wearing of trousers among Maasai men, and even a proposed exclusion from public service of those wearing traditional dress (Talle 1999).

Several aspects of continuity are evident between late colonial and postcolonial African government policy and development ideology (Young 2004; Mamdani 1996). Both the colonial and maendeleo development models emphasized formal education (in a national language), religious conversion, and agricultural commercialization. They also tended to view "tradition" as static and unchanging, and as such to posit it in opposition to their models of progress. This continuity also characterized the approach of postindependence governments to FGC. In 1970, for example, outbreaks of the genital infection known locally as lawalawa occurred in Dodoma and Singida in central and northern Tanzania among the Nyaturu ethnic group (Omari 1974) ${ }^{7}$ This outbreak led to mass circumcisions because many people believed that genital cutting cured the disease. A study by the Tanzanian Anti-Female Genital Mutilation Network (AFNET) reports that as a result of the heightened visibility of the practice, the semimilitary Field Force Unit and police force were sent to Singida and Dodoma communities to forcibly stop the practice. According to an AFNET report (2004), during a period of six months many people-including circumcisers and parents and guardians of circumcised children-"were treated roughly, beaten, held in custody in police cells, and ultimately sent to court, where they were convicted and given jail sentences. The AFNET report suggests, however, that "instead of stopping FGM once and for all, [the campaign caused it to go] underground until today. [People] have continued performing it secretly." These types of state interventions suggest that the methods used to undermine FGC and other minority cultural practices during the first twenty years of independence in Tanzania echoed their colonial predecessors. In neither period did interventionist measures succeed in stopping FGC: instead they drove the practice underground.

\section{"New" Development Ideologies: Civil Society}

Since the 1980s, dependence on external aid and economic liberalization has weakened the grip of many African states on development initiatives. Tanzania's second president, Ali Hassan Mwinyi, initiated a move away from ujamaa toward economic liberalization and a reduced state bureaucracy, a policy that has been continued by his successors. Some commentators predicted that these political and economic adjustments would also lead to 
social change through the emergence of a civil society composed of bourgeois institutions that would take on the development roles previously regarded as the province of the state (Hyden 1983). Indeed, following the introduction of structural adjustment policies, a plethora of development organizations emerged, many offering services or education in areas such as literacy, hygiene, sexual health, and agriculture. Some civil society organizations offer religious guidance or advance human rights concepts and many promise to emancipate women. The new lexicon of development, with its reification of civil society, emphasizes respect for "culture" and "tradition." Yet this language of inclusion often disguises a continued assault on Maasai culture as "primitive" by civil society institutions including schools, religious institutions, organizations working with local authorities, and the media. While there are a growing number of indigenous pastoralist development organizations (Hodgson 2001a:230-40), many of these groups are led by elite men. Despite the Poverty Reduction Strategies introduced in Tanzania from 2001 and supported significantly by civil society organizations, rising mortality rates during childbirth and early childhood suggest that women and children in poor rural communities continue to bear the brunt of neoliberal economic policies (Rusimbi 2006:53).

When development initiatives and anti-FGC campaigns are launched in the context of declining service provision, it is hardly surprising that these projects are regarded with suspicion by many rural Maasai. Many campaigns seeking to end FGC in Maasai communities may be associated with previous development initiatives that have sought to transform, "modernize," and "civilize" these rural communities, often with negative consequences. Projects that remove Maasai from their land and efforts to enforce school attendance are particularly controversial; these campaigns figure centrally in Maasai communities' fears of cultural and physical destruction. We argue below that in this context, contemporary anti-FGC campaigns can at times lead to the politicization of the practice, as did some of their colonial and postcolonial predecessors. First, we will explore how Maasai concepts of change and modernization are posited in opposition to the dominant discourse of maendeleo.

\section{“Our Traditions Have Always Been Modern": Maasai Communities in the Monduli Region}

Images of the "backward" Maasai are not limited to the colonial state or Western observers; they also permeate Tanzanian discourses of modernity and efforts by colonial and postindependence governments to repress "traditional customs" in the name of development. As Kenny (1981) notes, indigenous people often come to represent the "mirror in the forest": the image against which people who consider themselves civilized measure their own moral and material progress. Talle (1999:203) argues that "by being 'traditional,' the pastoralist way of life brings zamani (long ago) into sasa 
(now), a continuity that cannot be accommodated within the development discourse of progress."

The social construction of Maasai otherness is, of course, a complex and dynamic process. As the proponents of maendeleo reify "the traditional," so do the Maasai who are subject to their gaze. As "traditional practices" are attacked, they may also increasingly come to be seen as intrinsic to pastoralist culture and identity by rural Maasai themselves. Thus "cultural" practices that were once fluid, changing, and complex become part of a symbolic battleground where "Maasai culture" must be defended against the onslaught of development. As Hodgson (2001a) and Talle (1999) have pointed out, many rural Maasai increasingly come to view themselves in opposition to the ormeek ("Swahili" or "not Maasai") town dwellers who accept the maendeleo model of progress by wearing Western clothes, using pharmaceuticals rather than herbal medicines, and accepting world religions, particularly Christianity. ${ }^{8}$

This emphasis on upholding tradition in defiance of maendeleo serves to obscure alternative discourses of development that are prevalent within Maasai society. In contrast to the dominant language of maendeleo, change among Maasai communities in northern Tanzania is expressed by the Maa concept of enkisasai (new or modern), which emphasizes renewal, modification, and revitalization of that which is old. Maasai ideas about dress illustrate the concept of enkisasai at work. Most town dwellers in northern Tanzania regard modern dress as Western clothing. For most rural Maasai, however, to dress in a modern way is to wear Maasai fashion for the appropriate age-set. Perceptions of cattle also demonstrate enkisasai. In much of Tanzanian society, Western agricultural techniques are viewed as "modern" farming methods, regardless of whether they are appropriate to local conditions. Maasai pastoralists, however, favor cattle bred specifically for local environmental conditions, and these cattle are perceived as "modern."

In the same way, circumcision ceremonies constantly change and "modernize." A 2006 discussion group on female circumcision among Maasai community members in upper Monduli illustrates this point. Participants reflected on the ways in which female initiates (or isipolio-sing. esipoliei) in past generations would wear ceremonial orkila (leather robes with bead embroidery). In recent years, however, the orkila has become much less significant in initiation ceremonies and many people now opt to use enanga, clothes of similar design made from brown or black cloth. Initiation ceremonies have changed in other ways, too. As cattle and other resources have become scarce in many Maasai communities, a father is no longer always expected to perform the ceremony of orkiteng londomono, the slaughter of an ox before the circumcision ceremony (authors' field notes, Aang Serian Seminar, Eluwai Village, Monduli Juu Ward, Feb. 9, 2006).

In Maasai society, changes in circumcision ceremonies are typically described in terms of changes to the local environment and ecology rather than in the language of law or rights. For example, during a meeting in 
2006 of Maasai circumcisers intending to give up their practice, a circumciser explained that when girls are cut they lose a lot of blood. As a result, some initiates faint. To restore their energy, the girls are given cows' blood mixed with milk. However, this circumciser remarked that she had recently found this treatment to be less effective; the cows had become so thin that their milk did not contain enough fat. The circumcisers considered this a good reason to modify the initiation ritual by abandoning genital excision (authors' field notes, Eluwai, Monduli District, July 7, 2006).

The idea of a static canon of tradition conceals a consistent process of change and modernization within Maasai communities. We argue that antiFGC interventions that engage with Maasai ideas about change in ways that refer to the local context, including changes in the ecology and physical environment, are most likely to be effective. In the next sections we examine the language and methods of contemporary anti-FGC campaigns and suggest ways in which they might be modified to take these concerns into account.

\section{Contemporary Anti-FGC Campaigns}

Like their colonial predecessors, contemporary campaigners working to discourage FGC have employed a wide range of strategies, including criminalization and educational initiatives. Moreover, many contemporary activists utilize the framework of human rights and some have promoted "culturally sensitive" alternative ceremonies. Commentators and campaigners disagree on the success of anti-FGC programs. Our purpose here is not to undertake a definite evaluation of anti-FGC projects in northern Tanzania; instead we examine the politicized underpinnings of anti-FGC development practice.

\section{Legal Penalties}

Boyle and Preves (2000) attribute the adoption of anti-FGC measures by African governments between 1980 and 1998 primarily to Western pressure. Notably, United States congressional legislation in 1996 prohibited the practice domestically, while also supporting loans distributed through the IMF and the World Bank conditional on anti-circumcision campaigns on the part of the foreign governments (Boyle et al. 2001). Therefore, the Tanzanian government's efforts to criminalize FGG in the 1990s were likely designed primarily to fulfill its obligations to international institutions rather than to respond to local needs and views.

Tanzanians convicted of practicing female circumcision currently face up to five years imprisonment and/or a fine of 300,000 Tanzanian shillings (currently around US\$260) under the Sexual Offence Special Provision Act (Section 169A, Tanzania Penal Code, July 1998 (see Rahman \& Toubia 2000:223). This is a hefty fine in a country where the monthly national min- 
imum wage for rural workers in 2008 was 80,000 Tanzanian shillings (approximately US $\$ 70$ ). While it is hard to establish how widely and thoroughly current anti-FGC laws are enforced, journalists and NGOs report that parents and circumcisers have on various occasions been convicted, fined, and imprisoned (interview with AFNET regional coordinator, Arusha, June 22, 2006; Guardian of Dar es Salaam 2006). Moreover, according to the AFNET regional coordinator girls are encouraged to report their parents to the local authorities or anticircumcision NGOs like AFNET. Girls can also face compulsory checks in school to determine whether they have been circumcised (interview with director, Women In Action, Arusha, June 24, 2006). Despite such high-profile initiatives targeted at those who perform FGC, Tanzanian police and law enforcement authorities lack mechanisms to deal with girls seeking protection from FGC. Girls are often returned to their families or communities, leaving them at risk of FGC, early marriage, and punishment. This lack of enforcement also gives a contradictory message about the government's commitment to ending FGC (LHRC 2004; IRIN 2005).

There is little evidence to suggest that recent measures to criminalize female circumcision have been more effective than colonial interventions or the Tanzanian military's response in the 1970s. Daniel Ole Njoolay was a long-serving regional commissioner of Arusha and Mwanza, where he was a strong advocate of development initiatives. Reflecting the politics and ambiguity of ethnic identifications in northern Tanzania, he refers to himself as Maasai but was described by a Monduli Maasai leader whom we consulted as a member of the Arusha ethnic group. In 2002 Ole Njoolay argued that the practice remained "rampant" because practitioners had simply developed tactics to evade the laws, which often resulted in more harm than that caused by the open practice (Bwire 2002). FGG conducted secretly in small hospitals or by "mobile FGC clinics, in which nurses and clinicians move from village to village," is also reported in Kenya (Ochieng Ogodo 2005).

If anticircumcision laws are often ineffective in their objective of eradicating female circumcision, this does not mean that they are irrelevant. In fact, these policies may have important unintended consequences. There are reports that some adult women in Kenya are circumcised in order to evade laws forbidding genital excision for girls under the age of 18 (Kunyiha-Karogo 2007). The circumcision of married women during childbirth was also reported to us in Arusha (interview with director, Women in Action, Arsuha, June 24, 2006). The same interviewee also told us that children of various ethnic groups in the region are circumcised at increasingly young ages, and sometimes even at birth, in order to avoid government efforts to detect FGC in school-age children. Mayombo (2002) reports that "in the Singida region in central Tanzania, people circumvent the [FGC] law by privately cutting baby girls when they are a few days old." Thus, as in the past, high-profile measures involving the police or military can drive the practice underground and promote the circumcision of young children. 
These accounts are substantiated by the 2008 CEDAW country report on Tanzania.

Such responses to anti-FGC laws also fundamentally change the cultural meanings and character of female initiation rites. Referring to the 1956 Meru ban, Thomas suggests that when "female initiation was driven 'underground,' [the ritual was] stripped of its attendant celebrations and teachings, and reduced to the clandestine performance of excision" (2003:90). Defiance of the ban on excision reduced previously complex initiation rites to genital cutting alone, often among prepubescent girls. In situations in which excision comes to be seen as the central marker of group membership-to the extent that even babies must be circumcisedthe significance of FGC as a generational rite of passage is undermined. Newborns do not mysteriously become women upon circumcision in any community, while circumcision of grown women is not a rite of passage.

The relationship between anti-FGC campaigners and the police can also be controversial. Some NGOs, such as the Narok-based Tasaru Ntomonok Initiative (TNI), offer accommodation to girls fleeing forced FGC and rely on police support. In Uganda, where there is no legislation specific to FGC, the UNFPA-funded REACH project has argued that legal penalties against circumcisers are essential (Kirunda 2007). However, police involvement can also have negative consequences, including making the process of reconciliation between "rescued" girls and their communities more difficult (Kunyiha-Karogo 2007). Furthermore, indigenous organizations may hesitate to support the prosecution of community members. Members of a Maasai-led NGO based in Monduli and Arusha explained this concern about police involvement in correspondence with their donor: "If we were seen to be advocating for legal sanctions against offenders, and/or reporting them to authorities, Aang Serian would come to be regarded as an enemy-siding with the government and urban-based organizations to destroy the Maasai culture and identity" (Aang Serian, correspondence with Equality Now, Dec. 3, 2007).

Despite strong support among many sections of the Maasai community for their work in the Monduli District, Aang Serian activists believe that if their organization were involved in the prosecution of community members, its anti-FGC campaigns would no longer be effective. Indeed, such activities could provoke local protests and reprisals against the organization. NGO activists based in Narok, Kenya, similarly felt that interventionist approaches involving police could damage the status of an organization that seeks to represent itself as responsive to Maasai community concerns (authors' field notes, Narok, Kenya, Aug. 10, 2006). While laws against FGC can add credibility to anti-FGC campaigns, high-profile campaigns and arrests by police can also be extremely counterproductive. Criminalization also potentially undermines the methods of indigenous activists to effect change from within Maasai communities. 


\section{Resisting with Rights}

"Women's Rights" have arguably become the most important way to articulate the anti-FGC message. Media reports, educational programs, and NGO campaigns emphasize women's rights over their own bodies. For example, the Narok-based TNI NGO distributes posters reading "a girl has the right to refuse circumcision." Maasai girls at the NGO-run Rescue Centre in the same area are asked to repeat the slogan "maisha yangu, mwili wangu, haki yangu," or "my life, my body, my rights" (authors' field notes, Narok, Kenya, Aug. 7, 2006; Aang Serian 2006a).

Scholars have long debated the cultural specificity of human rights concepts. While we make no attempt to address this contentious debate here, it is important to recognize that calls to end female circumcision are often made in a language that, for many rural Maasai, may be confusing, unfamiliar, and associated with "outsiders." The rhetoric of "rights" may be closely associated with local, national, and international governmental and nongovernmental institutions (including service providers, aid workers, local charities, and churches) whose interventions are seen as undermining the physical and cultural survival of rural Maasai. The concept of women's rights in terms of individual choice is not one that readily translates into the Maa language. An individual's social status in Maasai society is typically defined in terms of his or her familial relationships. Women are commonly regarded as the domain of their fathers and the local moran (warriors) until transferred to their husbands (Chieni \& Spencer 1993). Marriages are typically polygamous, and women tend to be several generations younger than their husbands, who customarily refer to them as "my child." Similarly, the concept of "bodily integrity" that is intrinsic to human rights-based approaches may have conflicting local meanings. In Maa the family is described as a "body" in which the position of a wife is that of the "neck" to the husband's "head." During an FGC seminar in the rural Maasai village of Eluwai, participants pointed out that husbands are admonished to recognize and value their wives' support, "as the neck supports the head" (authors' field notes, Kitumusote Centre, Eluwai, Monduli, Feb. 9, 2006).

Rights-based approaches may also clash with local views of social life. Participants at the Eluwai seminar, for example, pondered the paradox of women's rights by reflecting on how female initiation allows a woman to be accepted as an adult who is able take part in these "bodily" relationships. In many communities, uncircumcised women are effectively barred from marriage. This means that a woman would be unlikely to choose to exercise her individual right to resist circumcision over her right to community membership (authors' field notes, Kitumusote Centre, Eluwai, Monduli, February 9, 2006). Maasai women from upper Monduli who analyzed an anti-FGC leaflet were perplexed by the use of the language of rights, one asking, "whose right? God's right?" (authors' field notes, Upper Monduli, June 23, 2006). The language of rights and individual choice is therefore 
likely to be ineffective if these notions are not discussed with reference to women's social status and communal rights to cultural self-determination.

\section{Approaches Focusing on Health}

FGC can have serious consequences for women's health. Short-term risks include excessive bleeding during the operation, shock, infection, and septicemia. Long-term problems include potential infertility, pain during sex, urinary tract infections, fistulae, difficulties in menstruation, and complications during childbirth (IRIN 2005). Despite a lack of definitive clinical evidence, some suspect that female excision can spread HIV/AIDS when circumcisers use the same razor for several girls or when a circumcised woman bleeds during sexual intercourse (Keown 2007).

Anti-FGC campaigns that focus on health are often considered less controversial than rights-based approaches; they involve less implied value judgments and are easier for local people to accept. Some NGOs emphasize the potential links between HIV/AIDS and FGC and combine education programs on these issues. Aang Serian has found it useful to link these issues in order to convince Maasai communities that FGC is a problem that affects both men and women. Moreover, the increased risk of HIV/AIDS transmission for circumcised women helps activists convince communities that immediate rather than gradual change is imperative (Aang Serian correspondence with Equality Now, November 2007).

However, health-based anti-FGC campaigns are rarely accompanied by efforts to improve other aspects of women's health. Women who have undergone FGC often have very limited access to health care. For example, the 2004-5 TDHS shows that women from lower income groups, those with lower levels of formal education, and those living in rural areas were far less likely than their wealthier, more educated, urban contemporaries to deliver their child in a health facility, to receive assistance from trained personnel, or to receive antenatal or postnatal care (National Bureau of Statistics 2005) ${ }^{9}$ Problems related to FGC are themselves compounded by inadequate provision of rural health facilities.

In societies with very high FGC prevalence, convincing people of the seriousness of the related health problems can also pose a challenge. Difficult childbirth and long postpartum recovery periods-which are often exacerbated by FGC-tend to be regarded as the norm. Thus communities may not attribute the severe complications of FGC to the procedure itself. To complicate matters, many rural Maasai women we consulted believed that genital excision actually has health benefits, such as preventing the socalled lawalawa infections. It is also commonly thought that uncircumcised women give birth to blind babies (authors' field notes, Monduli, June 24, 2006; Narok, Aug. 8, 2006). These concerns were frequently raised during Aang Serian's seminars. One participant commented that "there are some diseases that affect uncircumcised young people. For example, in some 
tribes, boys get sick and do not recover until they are circumcised. Won't our girls get sick?" Another participant asked "Why is it that we go to hospital and it doesn't cure this disease, but circumcision cures it?" A further participant wondered, "have the white people got any medicine for [lawalawa], or are they just telling us to stop circumcision?" (authors' field notes, Lashaine Village, Sepeko Ward, July 14, 2006). The last comment, made at a seminar convened and run by village leaders, demonstrates the widespread feeling that anti-FGC campaigns are imposed by "outsiders." While the ailments known as lawalawa and sexually transmitted diseases that cause blindness in babies can often be treated with antibiotics, most rural Maasai have limited access to dispensaries and health care professionals. As the seminar comments show, people are suspicious of being told to stop using methods that have apparently proven effective when they are offered no alternative in the form of improved health care facilities. FGC campaigners must therefore understand local conceptualizations of diseases like lawalawa in order to propose alternative methods for treating vaginal infections and to challenge powerful arguments in favor of female circumcision.

Despite some efforts to combine education about FGC and HIV/AIDS, these approaches rarely address local beliefs that FGC limits female promiscuity and the spread of sexual diseases by reducing women's enjoyment of sex. Interestingly enough, in discussions about the reasons for promiscuity and the spread of sexual diseases in Monduli, most women, quite accurately, cited poverty and low social status. In a women's group discussion at a seminar in Lashaine Village, for example, participants said that some husbands encouraged their wives to sell sex to earn money. Drunkenness was also cited as a common trigger for men to force women into sex. Discussants also spoke of widows of HIV/AIDS victims who were forced to leave their villages and enter the sex trade in towns (authors' field notes, Lashaine Village, Sepeko Ward, July 14, 2006).

Under these circumstances, female enjoyment of sex is clearly irrelevant to the spread of HIV/AIDS. It is nonetheless vital that anti-FGC campaigners address common beliefs about circumcision and suggest alternative ways to treat and limit the spread of sexually transmitted diseases. Similarly, FGC campaigners must untangle local understandings of diseases like lawalawa and their connections to FGC. Most important, no campaign can be successful without addressing the inadequate provision of health care in Maasai communities and recognizing the complex links between poverty, women's social status, the spread of HIV/AIDS, and attitudes toward FGC.

\section{Eradication via Education}

Many NGO workers and women's rights advocates call for "education" in the broadest possible terms as a strategy to end FGC. Because few girls in rural East Africa attend secondary school, many colonial and contemporary commentators have argued that FGC will decline when girls are educated. 
A telling example of this approach is an admonition of a district education officer in the Kuria region of Kenya: "Let us circumcise the minds of our daughters with quality education instead of subjecting them to this primitive culture... FGM is condemned worldwide and the local community should not stick to it" (cited in The Daily Nation 2005, emphasis added). Similarly, observers propose to address Maasai female circumcision (and women's problems more generally) by building more schools (e.g., Skaine 2005:154-55,170).

Yet evidence suggests that the relationship between formal education and female circumcision is far from clear. Nypan (1991) highlighted resurgent practices of FGC among educated girls in the Meru area of Tanzania in the late 1980s, even though their families often opposed the practice. Evidence from the Sabiny community in Uganda suggests, moreover, that educated community members do not necessarily oppose FGC. In fact, professionals, including professors, magistrates, and local government officials, have at times opposed campaigns to end FGC in the Kapchorwa District of Uganda (Thuo 2007). In addition, calls for schooling often fail to explore the complex and politicized roles of educational institutions. The dynamics of education-based approaches are particularly complex in rural Maasai communities. As Lawi (2005) points out, Tanzanian school curricula are not typically designed to teach pupils about their ethnic heritage; in general, cultural differences are subsumed within a broader narrative of national or pan-African experience. In the Monduli region, church-run educational projects have historically emphasized conversion (Hodgson 2005:115), and both state and church-run schools explicitly prohibit the Maa language and local dress codes, including jewelry and hairstyles that serve as important religious and generational markers in Maasai society. ${ }^{10} \mathrm{~A}$ male Maasai activist and community leader in Monduli, Tanzania, reflected critically on his own experience of formal schooling:

\begin{abstract}
After we were circumcised, we were supposed to grow our hair long, to show that we had a special status in the community. But our teacher made us stand in a line, shaved off our sacred hair and cut off our jewelry, and threw it all into the latrine. He told us we could never expect to make progress in life, as long as we clung to these outdated superstitions (Lesikar Ole Ngila, cited in Aang Serian 2006b).
\end{abstract}

In the absence of community-based schools, parents often have little choice but to send their children to boarding schools, but Maasai parents often view them with skepticism, if not outright suspicion, and are sometimes reluctant to send their children at all (Bentsen 1989). And while anti-FGC advocates hope that educated Maasai girls will return from their boarding schools to challenge FGC and educate their peers (Skaine 2005:156), the experience of formal education often has the opposite effect of isolating Maasai youth from their home environments. While educated Maasai girls 
may indeed come to repudiate the practice of circumcision, they may also break away from their rural communities and even repudiate their families as "backward." Implicit in the send-them-to-school argument is the idea that girls should be "educated out" of their culture, often to the extent of rejecting their Maasai identity completely. As a result, many rural Maasai view government, church, and NGO-run schools with trepidation. Although the provision of schools is vital, these facilities cannot always provide an immediate solution to FGC.

\section{Anti-FGC Education}

Increasingly, NGOs and governments promote educational programs specifically designed to dissuade communities from practicing female circumcision by highlighting its dangers. Since the 1990s anti-FGC seminars have become commonplace in northern Tanzania. The AFNET regional coordinator (interview, Arusha, June 22, 2006) estimates that over 95 percent of the population in the Arusha area has received some form of structured anti-FGC education.

Hernlund (2000:241) notes that anti-FGC campaigns in the Gambia made excessive use of informational materials designed outside West Africa that often appeared irrelevant to Gambian women. Similar dynamics are evident in northern Tanzania. AFNET organizes many anti-FGC campaigns and seminars across the Arusha region and produces campaign literature. While researching local anti-FGC projects, we showed an AFNET leaflet apparently aimed at indigenous women to a group of Maasai women in upper Monduli. The leaflet was written in Swahili and therefore not comprehensible to most Maa-speaking women. However, its illustrations received much scrutiny. The women in upper Monduli noted that in an illustration of the emurata (circumcision ceremony), the enkamoratani (circumciser) pictured was not wearing ceremonial clothing. She was also wielding the wrong kinds of instruments and was not sitting in the proper position in the doorway of the hut. The girl who was to be circumcised looked older than circumcision age. Furthermore, the women pictured were not wearing Maasai clothes, and unlike Maasai women at circumcision ceremonies, they did not have shaved heads. Also missing was a green branch of oloilalei (olive) planted in the ground outside the hut. The leaflet also depicted people attending an anti-FGC meeting. The women pointed out that all those pictured were ormeek (wearing Western clothing) and therefore could not be truly Maasai. Finally, the people attending the meeting were depicted as young, whereas at a Maasai meeting an elder would have been involved in explaining and teaching others. Tellingly, there was no attempt by the illustrators to portray the enlightened participants as either Maasai or "traditional." After the leaflet was translated to Maa and read aloud, the group felt that the text did not address the reasons for circumcising girls. Some women responded to the leaflet's text by saying that "parents don't subject girls to circumcision 
because they hate them but because they care about them and want them to be accepted and marry into good families." Local activists recommended that to be more persuasive, the leaflet should have emphasized the language of community over that of individual rights, stressing the problems that would affect the Maasai as a whole if FGC were not stopped (authors' field notes, Upper Monduli, June 23, 2006).

The reception of this leaflet in upper Monduli sheds light on the assumptions and methods of anti-FGC education. Many anti-FGC educational programs continue to present FGC as an unchanging, backward practice that tenaciously persists, despite well-intentioned development efforts, simply because of a lack of information or understanding of its dangers. AntiFGC education programs therefore focus on remedying their target audience's supposed ignorance. This presumption of ignorance stands at odds with the proliferation of anti-FGC programs past and present. For example, despite the pervasiveness of anti-FGC education in Arusha described by the AFNET regional coordinator, he estimated that the prevalence of FGC in the area was at least 50 percent and possibly increasing.

Anti-FGC education projects in the Arusha area are shaped by such presumptions of ignorance, which are constantly linked to the ideas of backwardness and stubborn traditionalism discussed above. For example, former Regional Commissioner Daniel Ole Njoolay encouraged anti-FGG education in the area to combat "primitive" beliefs (Bwire 2002). In 2003 a facilitator at a seminar run by the International African Culture NGO in Shiboro village, Arumeru, Tanzania, described FGC as "barbaric." Immediately, around two-thirds of the local women in attendance walked out. Outside, the women protested that circumcision curbed promiscuity and was an important part of female initiation. Rather than specifically addressing these objections, local church leaders simply argued that the protesting women were "backward" and described their objections as motivated by "ignorance" (Arusha Times 2003).

\section{Female Initiation and Instruction}

While anti-FGC campaigners have emphasized formal education as a way to eradicate FGC, many ignore the educational elements of the initiation ceremony itself. Maasai circumcision is just one aspect of a series of complex rites that enable a girl to become an adult woman and fully-fledged community member. Circumcisers are not simply responsible for wielding razors; they are mature, respected community members. Parents trust circumcisers to instruct their daughters in Maasai values and adult responsibilities such as childcare and food preparation (see Russell-Robinson 1997:55; Mutisya 1996).

Anti-FGC initiatives that focus only on eliminating genital cutting fail to recognize the ways in which initiation enables girls to participate in their communities as adults. During an FGG seminar convened by Aang Serian 
NGO and a local women's cooperative in a small Maasai village in the Monduli District, a local leader pointed to this dilemma. He suggested that without the instruction period preceding circumcision, Maasai women might be "trapped in the middle," deprived of both traditional forms of instruction and formal education. He asked, "if you take this [female initiation] away, what are you going to give them?" (authors' field notes, Eluwai Village, Monduli, May 24, 2006).

\section{Eliminating FGC through Alternative Ceremonies}

Accordingly, anti-FGC advocates are increasingly recognizing the cultural importance of initiation rites. Several NGOs have developed alternative ceremonies to promote "circumcision through words." These ceremonies abandon excision but seek to retain other aspects of generational initiation rites such as celebration, seclusion, and instruction. These programs typically emphasize that "[their] campaign is not against [local] customs as a whole, merely against FGM" (IRIN 2005:13). Unlike many of the anti-FGC education programs discussed above, alternative ceremonies seek to "[capture] the cultural significance of female circumcision while doing away with the dangerous practices" (James 2002:105). Moreover, by retaining the period of seclusion, alternative ceremonies aim to retain the period of learning that accompanies initiation rites.

These initiatives are gaining popularity, notably in Kenya, where the first "circumcision through words" ceremony took place in 1996 in the Meru village of Gatunga near Mount Kenya. The program for initiates included a week's seclusion and training on reproductive health issues and HIV/AIDS, followed by festivities, singing, dancing, and gifts when the initiates returned to their home communities. The first ceremony also encouraged families from several ethnic groups in the area to participate in future alternative ceremonies (IRIN 2005; James 2002). When we visited in 2006 , TNI's Rescue Centre in Narok, Kenya, was using a similar alternative ceremony model as the culmination of a training program on health and reproductive issues for Maasai girls. This educational program was designed to replace the traditional period of instruction preceding circumcision for Maasai initiates.

Despite some promising indications, "alternative ceremonies," like other anti-FGC initiatives, are typically orchestrated by schools, churches, and NGOs-organizations that are often considered to be community "outsiders" (Mutisya 1996). As a result, these ceremonies often exclude or marginalize parents, former circumcisers, and other community members who would have been involved in a conventional ceremony. Many alternative rite-of-passage ceremonies strongly promote religious content or anti-FGC messages often associated with churches or advocacy groups. For example, participants in some Kenyan replacement ceremonies are asked to wear T-shirts bearing anti-FGC slogans. Replacement ceremonies that revolve 
primarily around the elimination of genital cutting risk being interpreted as vehicles to undermine minority cultures. Thus, like coercive government campaigns, replacement ceremonies may have counterintuitive outcomes. For example, one report suggests that some Kenyan communities have lowered the age of female circumcision in defiance of campaigns promoting alternative rites of passage among teenagers (IRIN 2005:7-8). However, some small-scale NGOs have attempted to develop alternative ceremonies that avoid such dilemmas. For example, members of the Narok-based NGO Maasai Education Discovery support alternative ceremonies without excision that take place within Maasai villages without the presence of "outsiders," carrying no explicit anti-FGC message, and involving former circumcisers, parents, and other members of the community who would normally be present at an initiation ceremony (authors' field notes, Narok, Kenya, Aug. 10, 2006).

The Maasai concept of enkisasai-societal change through the revitalization and adaptation of tradition - could also provide a model for ceremonies that are more likely to be acceptable in Maasai communities. Changing rite-of-passage ceremonies to exclude genital cutting could be compared with the transition from wearing the ceremonial beaded orkila to wearing the simpler enanga dress, or the gradual abandonment of the slaughtering of an ox before a circumcision ceremony. We discussed such changes with a group of circumcisers who had recently abandoned the practice in Eluwai in 2006. These women argued that female excision should be eliminated but that other important elements of the ceremony should remain unchanged. They emphasized that initiates should continue to be dressed in black, a color associated with the blessings of Enkai (or Engai, creator or god), with beaded headbands decorated with cowrie shells to represent female fertility. Livestock should still be slaughtered for communal feasts featuring singing and dancing. These continuities, the former circumcisers argued, would enable relatives and neighbors to participate actively in the redefinition of the initiates' identities and social roles. Furthermore, a branch from a sacred tree should still be planted outside the home of each initiate to mark her "planting" as a mature woman. ${ }^{11}$ The importance of instructing the initiates during their period of seclusion was also emphasized. The former circumcisers suggested that they should continue to teach the initiates about adult life, "good behavior and how to be a respectful Maasai woman." This discussion implied an acknowledgment that the primary purpose of female initiation is training in Maasai social norms, not genital surgery (authors' field notes, Eluwai, Monduli, July 7, 2006).

\section{Conclusions}

The possibility of divorcing the coming-of-age ceremony from the practice of FGC may seem optimistic, but some evidence suggests that it is indeed possible to disconnect genital excision from the social process of "becom- 
ing a woman." Maasai female initiation ceremonies are not static or unchanging rituals practiced by ignorant people. In fact, the Maasai concept of enkisasai illuminates how Maasai cultural practices constantly evolve and adapt to local circumstances. As discussed above, girls who are circumcised at a very young age, for example-whether to avoid detection by the authorities or to ward off the perceived risk of the diseases-do not become women in the eyes of their communities and girls typically participate in other coming-of-age ceremonies during puberty. It is possible, therefore, for Maasai communities to accept the modification of ceremonies, including generational initiation rites, as local circumstances change. Anti-FGC campaigners will continue to encounter difficult questions about the extent to which such cultural shifts are possible and sustainable within particular sociopolitical contexts, as well as how to tackle issues related to rites of passage such as early marriage. Nevertheless, we suggest that contextual approaches are likely to be more successful than campaigns that emphasize development that is posited in opposition to "traditional" culture.

Educational, religious, civil society, and governmental institutions can make invaluable contributions to efforts to eliminate FGC by ceasing to portray its practitioners as "primitive," "ignorant," and even "barbaric," words that echo the language of their colonial predecessors. These characterizations are misleading, ineffective, and counterproductive, as are governmental and nongovernmental initiatives that fail to respect the important cultural and communal functions of FGG ceremonies, such as intergenerational education. Also ill-advised are government and NGO-led campaigns against FGC that draw their language and strategies from human rights and maendeleo discourses. Such initiatives tend to position their organizers as "outsiders" in relation to rural "traditional" Maasai, thus also provoking negative associations among rural pastoralist communities in northern Tanzania. Because Maasai communities have regularly been targeted by such insensitive and even oppressive anti-FCG campaigns, the programs often have had effects opposite to those that were intended. Initiation rites often come to symbolize the preservation of Maasai identity and pastoralist values, driving FGC underground, leading to the circumcision of younger girls, and even increasing the incidence of genital cutting. As such, anti-FGC campaigns can never be just about female excision; they are inevitably embroiled in politicized struggles for Maasai cultural self-determination.

For these reasons, we maintain that anti-FGC campaigns in northern Tanzania must be rooted within the communities where these rites are meaningful. Rural Maasai must be involved in designing culturally appropriate alternatives to the practices they are being asked to abandon. Efforts to end FGC must distinguish carefully between genital excision and other aspects of Maasai female initiation ceremonies. Information campaigns must be tailored to reflect local beliefs about FGC and should employ language and frameworks that are accessible to their target audiences. We also suggest that the case for changes in female rites of passage in Maasai 
communities in northern Tanzania can be successfully made in the language of enkisasai, emphasizing the constant adaptation of Maasai cultural practices to changes in the local context and physical environment. Finally, campaigns against FGG must be accompanied by real improvements in the availability, accessibility, and cultural appropriateness of local health and educational services so that communities feel that they are being offered an alternative for the practices they are being asked to abandon.

The dilemmas faced by anti-FGC campaigners in northern Tanzania resonate with campaigns targeting other ethnic groups in different regions of Africa, including colonial and contemporary projects in Kenya, Uganda, and Sudan. As in Maasai communities, these anti-FGC campaigns often encounter resistance because of their associations with individuals and institutions perceived as "outsiders," including the colonial and postcolonial state, urban advocates of development and modernization, and religious groups. Campaigners must take these (perceived) associations seriously. Most urgently, those advocating against FGC must use locally appropriate language and terminology.

Our findings in northern Tanzania also have wider implications for debates about development theory and practice across disciplinary fields and campaign areas. While scholars and practitioners are increasing aware of the complex power relations involved in development discourse and practice, researchers have neither fully explored the practical manifestations of these dilemmas nor paid sufficient attention to alternative understandings of development and modernity among those who are the targets of development interventions. We suggest that scholars and practitioners adopt engaged interdisciplinary and ethnographic approaches to consider in depth the local meanings, historical context, and politicization of FGC and other cultural practices.

\section{Acknowledgments}

The authors wish to thank the members of Aang Serian NGO and Olomayani Women's Group in Tanzania, the editors of the African Studies Review, three anonymous reviewers, as well as Esmyr van Hees, Michelle Palo, Emily Gray, and Susie Goldring for comments and proofreading.

\section{References}

AFNET (Tanzanian Anti-Female Genital Mutilation Network). 2005. Report on the Situation of Female Genital Mutilation in Tanzania: A Study of Five Regions. Dodoma, Tanzania.

Aang Serian. 2006a. Report on Study Visit and Training Course on FGM and HIV/AIDS: Tasaru Ntomonok Intiative, Narok, Kenya. Arusha, Tanzania

Aang Serian. 2006b. Report on Progress and Aims of Noonkodin Secondary School. Arusha, Tanzania. 
Appadurai, Arjun. 1996. Modernity at Large: Cultural Dimensions of Globalization. Minneapolis: University of Minnesota Press.

Arush a Times. 2003. "Ilkiding Women March in Protest of Anti-FGM Efforts," August 2-8.

Bergner, Daniel. 2006. "The Call.” The New York Times Magazine, January 29.

Bentsen, Cheryl. 1989. Maasai Days. New York: Summit.

Boddy, Janice. 1991. "Body Politics: Continuing the Anti-Circumcision Crusade." Medical Anthropology Quarterly (n.s.) 5 (1): 15-17.

2007. Civilizing Women: British Crusades in Colonial Sudan. Princeton: Princeton University Press.

Boyle, Elizabeth Heger, Fortunata Songora, and Gail Foss. 2001. "International Discourse and Local Politics: Anti-Female Genital Cutting Laws in Egypt, Tanzania, and the United States." Social Problems 48 (4): 524-44.

Boyle, Elizabeth Heger, and Sharon E. Preves. 2000. "National Politics as International Process: The Case of Anti-Female-Genital-Cutting Laws." Law and Society Review 703: 703-37.

Bwire, Nyamanoko. 2002. "Genital Mutilations Still Rampant in Arusha Region." Arusha Times, February 23-March 1

CEDAW. 2008. "Concluding Observations of the Committee on the Elimination of Discrimination against Women: United Republic of Tanzania."

Chieni, T., and P. Spencer. 1993. "The World of Telelia: Reflections of a Maasai Woman in Matapato." In Being Maasai: Ethnicity and Identity in East Africa, edited by Thomas Spear and Richard Waller. Oxford: James Currey.

Cooper, Frederick. 2002. Africa Since 1940: The Past of the Present. Cambridge: Cambridge University Press.

Ferguson, James. 1990. The Anti-Politics Machine: "Development", Depoliticization, and Bureaucratic Power in Lesotho. Cambridge: Cambridge University Press.

Daily Nation. 2005. "Educate Daughters, Community Urged." Nairobi, December 28.

Geiger, Susan. 2005. "Engendering and Gendering African Nationalism: Rethinking the Case of Tanganyika (Tanzania)." In In Search of a Nation: Histories of Authority and Dissidence in Tanzania, edited by Gregory H. Maddox and James L. Giblin. Oxford: James Currey.

Gupta, Akhil, and James Ferguson, eds. 1997. Culture, Power, Place: Ethnography at the End of an Era. Durham, N.C.: Duke University Press.

Hernlund, Ylva. 2000. "Cutting without Ritual and Ritual without Cutting: Female 'Circumcision' and the Re-Ritualization of Initiation in the Gambia." In Female 'Circumcision' in Africa: Culture, Controversy and Change, edited by Bettina ShellDuncan and Ylva Hernlund. Boulder, Colo.: Lynne Rienner.

Herskovits, M. J. 1926. "The Cattle Complex in East Africa." American Anthropologist (n.s.) 28 (1): 361-88

Hodgson, Dorothy L. 1999. "Once Intrepid Warriors: Modernity and the Production of Maasai Masculinities.” Ethnology 38 (2): 121-50.

2001a. Once Intrepid Warriors: Gender, Ethnicity, and the Cultural Politics of Maasai Development. Bloomington: Indiana University Press.

2005. The Church of Women: Gendered Encounters between Maasai and Missionaries. Bloomington: Indiana University Press.

Hodgson, Dorothy L., ed. 2001b. Gendered Modernities: Ethnographic Perspectives. New York: Palgrave. 
Hyden, Goran 1983. No Shortcuts to Progress: African Development Management in Perspective. London: Heineman.

IRIN (U.N. Integrated Regional Information Networks). 2005. Razor's Edge: The Controversy of Female Genital Mutilation. New York: U.N. Office for the Coordination of Humanitarian Affairs. www.irinnews.org.

James, Stanlie M. 2002. "Listening to Other(ed) Voices: Reflections around Female Genital Cutting." In Genital Cutting and Transnational Sisterhood: Disputing US Polemics, edited by Stanlie M. James and Claire C. Robertson, 87-113. Champaign: University of Illinois Press.

Kenny, M. G. 1981. "Mirror in the Forest: Dorobo Hunter-Gatherers as an Image of the Other." Africa 51: 477-96.

Keown, Mary Katherine. 2007. "Tanzania: The Link between Female Genital Mutilation and HIV Transmission." Arusha Times, November 17.

Kouba, Leonard J., and Judith Muasher. 1985. "Female Circumcision in Africa: An Overview." African Studies Review 28 (1): 99.

Kirunda, Kakaire A. 2007. "Uganda: The Push for an Anti FGM Law Continues." The Monitor, Kampala, May 15.

Kunyiha-Karogo, Judith. 2007. "Working with Maasai Communities." Paper presented at UNFPA Global Technical Consultation on Female Genital Mutila tion/Cutting, Addis Ababa, July 30-August 3.

Lawi, Yusuf. 2005. "Between the 'Global' and 'Local' Families: The Missing Link in School History Teaching in Postcolonial Tanzania." In In Search of a Nation: Histories of Authority and Dissidence in Tanzania, edited by Gregory H. Maddox and James L. Giblin. Oxford: James Currey.

Legal and Human Rights Centre. 2004. The Legal Process: Can It Save Girls from FGM? A Case of Three Maasai Girls in Morogoro. A Report on the Enforcement of the FGM Law. Dar es Salaam: The Legal and Human Rights Centre.

Mamdani, Muhammad. 1996. Citizen and Subject: Contemporary Africa and the Legacy of Late Colonialism. Princeton: Princeton University Press.

Mayombo, Alakok. 2002. "Emergency FGM Rescue Operation Fails in Tanzania." Afrol News/Panos, May 29. www.afrol.com.

Mutisya, P. Masila. 1996. "Demythologization and Demystification of African Initiation Rites: A Positive and Meaningful Aspect Heading for Extinction." Journal of Black Studies 27 (1): 94-103.

National Bureau of Statistics. 2005. Tanzania Demographic and Health Survey 2004/5. Dar es Salaam, Tanzania. www.nbs.go.tz.

Nypan, A. 1991. "Revival of Female Circumcision: A Case of Neo-Traditionalism." In Gender and Change in Developing Countries, edited by K. Stolen and M. Vaa. Oslo: Norwegian University Press.

Omari, C. K. 1974. "In the Name of Culture." Tanzania Notes and Records 74: 11-17.

Rahman, Anika, and Nahid Toubia. 2000. Female Genital Mutilation: A Guide to Laws Worldwide. London: Zed Books.

Rusimbi, Mary. 2006. "Financing the Protocol: Consideration for Influencing Budgets from Experiences in Tanzania." In Breathing Life into the African Union Protocol on Women's Rights in Africa, edited by Roselynn Musa, Faiza Jama Mohammed, and Firoze Manji, 38-46. Oxford: Solidarity for African Women's Rights and African Union Women, Gender and Development Directorate.

Russell-Robinson, Joyce. 1997. "African Female Circumcision and the Missionary Mentality." Issue: A Journal of Opinion 25 (1): 54-57. 
Skaine, Rosemarie. 2005. Female Genital Mutilation: Legal, Cultural, and Medical Issues. Jefferson, N.C.: McFarland.

Shell-Duncan, Bettina, and Ylva Hernlund, eds. 2000. Female 'Circumcision' in Africa: Culture, Controversy, and Change. Boulder, Colo.: Lynne Rienner.

Talle, Aud. 1999. "Pastoralists at the Border: Maasai Poverty and the Development Discourse in Tanzania." In The Poor Are Not Us: Pastoralism and Poverty in Eastern Africa, edited by David Anderson and Vigdis Broch-Due. Oxford: James Currey.

Thomas, Lynn. 2000. "Ngaitana (I Will Circumcise Myself): Lessons from Colonial Campaigns to Ban Excision in Meru, Kenya." In Female 'Circumcision' in Africa: Culture, Controversy and Change, edited by Bettina Shell-Duncan and Ylva Hernlund. Boulder, Colo.: Lynne Rienner.

2003. Politics of the Womb: Women, Reproduction, and the State in Kenya. Berkeley: University of California Press.

Thuo, Margaret. 2007. "FGM/FGC Global Consultation: The Politics of FGM/FGC Partnership Building and Community Accountability Mechanism. Case Study, Uganda." Paper presented at the UNFPA Global Technical Consultation on Female Genital Mutilation/Cutting, Addis Ababa, July 30-August 3.

Young, Crawford. 2004. "The End of the Post-Colonial State in Africa? Reflections on Changing African Political Dynamics." African Affairs 103: 23-49.

UNICEF. 2005. Female Genital Mutilation/Cutting: A Statistical Exploration. www.unicef. org.

United Republic of Tanzania. 2003. The National Plan of Action to Accelerate the Elimination of FGM and Other Harmful Traditional Practices in Tanzania 2001-2015. Dodoma, Tanzania: Ministry of Community Development, Gender and Children and Ministry of Health.

Wolf, Eric. 1982. Europe and the Peoples without History. Berkeley: University of California Press.

\section{Notes}

1. The terminology surrounding the various procedures known as female circumcision, female genital mutilation (FGM), or female genital cutting (FGC) is controversial (Shell-Duncan \& Hernlund 2000:3-7). We use the term FGC here to reflect the language adopted by recent anthropological studies.

2. Though various types of circumcision are practiced in Tanzania, the TDHS for 2004-5 reports that between 89.8 and $96.2 \%$ of circumcised women surveyed across all age groups undergo either "modified sunna" surgeries (full or partial removal of the clitoris) or clitoridectomies (removal of the clitoris and the labia minora entirely or in part). These types of circumcisions account for $94.9 \%$ of surgeries in Arusha and $86.4 \%$ in Manyara. Other surgeries practiced in Tanzania include "mild sunna" (surgeries involving the prepuce of the clitoris) and infibulation (the removal of the clitoris, the labia minora, and the inner walls of the labia majora, after which the labia majora are sewn together to cover most of the vagina) (National Bureau of Statistics 2005:table 13.2; Kouba \& Muasher 1985).

3. Many African countries with a widespread incidence of FGC have adopted antiFGC policies, laws, or programs (Boyle et al. 2000, 2001). Twenty-three African states including Tanzania have ratified the 2003 Protocol on the Rights of 
Women in Africa, known as the Maputo Protocol, which commits governments to enforcing anti-FGC laws, promoting public awareness, and protecting victims. FGC was also explicitly classified as a form of violence against women at the 1995 U.N. Conference on Women in Beijing. While they do not explicitly mention FGC, other international instruments invoked by anti-FGC campaigners include the CEDAW convention of 1981, which calls on states to "modify social and cultural patterns of the conduct of men and women," and the 1984 U.N. Convention on Torture (Shell-Duncan \& Hernlund 2000:28-29). The 1994 U.N. Declaration on the Elimination of Violence against Women also refers to the harmful effects of certain traditional or customary practices.

4. Interviews with members of the Tanzanian National Coalition against FGM, including the LHRC FGM coordinator, Dar es Salaam, May 11, 2007; TAMWA FGM coordinator, Dar es Salaam, May 15, 2007; and TAWLA FGM coordinator, Dar es Salaam, May 22, 2007.

5. "Cultural conservatism" has been a constant theme in discussions of pastoralist societies since Herskovits (1926) argued for the inclusion of cultural values in the study of material culture. Herskovits has often been interpreted as arguing that pastoralists' attachment to their cattle was "irrational" and that only a change in social and cultural forms would prompt transition to a more "rational" economic system. While this interpretation has been refuted, it continues to exert influence in policy toward pastoralists.

6. See Hodgson (2001a) on the history of the Maasai.

7. The term lawalawa is widely used in northern Tanzania among the Maasai and other ethnic groups to describe infections and diseases that cause vaginal itching. During our focus group discussions in the Monduli region, the term was used by Maasai women to describe conditions that resembled thrush, trichomonas vaginalis, and candida (authors' field notes, Monduli, June 24, 2006).

8. Ormeek (or irmeek) is a Maa term usually used to describe people wearing Western clothing, including "Maasai who [have] adopted European clothes and ways, including education and Christianity," and as a "derogatory name for 'Swahilis' or 'strangers"' (Hodgson 2005:122,130).

9. Statistics for death during childbirth, like those for adult mortality in general, must be interpreted with caution. Although these measurements were included in both the 1996 and the 2004-5 TDHS, underreporting is thought to have been higher in the first survey. Nonetheless, a comparison of the two surveys shows a $68 \%$ increase in female mortality rates compared with a $24 \%$ increase in male mortality rates from the 1996 TDHS rates in the age-group 15 to 49 . This might be attributed to increased rates of HIV/AIDS infections among women rather than deaths by childbirth. Nonetheless, these figures do indicate a rise in mortality rates among women of childbearing age (National Bureau of Statistics 2005: chap. 14.2; see also Rusimbi 2006).

10. Although it is often assumed that Christian converts abandon "traditional practices," the TDHS of 2004-5 recorded that $19.5 \%$ of Protestants and $14.2 \%$ of Catholics were circumcised, compared to $11.13 \%$ of Muslims and $12.3 \%$ of those with no religion.

11. The concept of "planting" (e-unoto in Maa), represented by the symbolic planting of a tree branch, is also an important aspect of the transition from junior to senior warriorhood among Maasai men. 